\title{
CRÍTICA E CRISE: TEORIA DA LITERATURA E HISTÓRIA DA CRÍTICA
}

\section{CRITIQUE AND CRISIS: THEORY OF LITERATURE AND HISTORY OF CRITICISM}

Thiago Santana ${ }^{1}$

\begin{abstract}
Resumo: Resenha de Teoria da Literatura e História da Crítica: momentos decisivos, de Nabil Araújo. Discutirei, capítulo a capítulo, os problemas centrais tematizados no contexto da obra, buscando lançar luz sobre a rede de referências teóricas, críticas e filosóficas mobilizadas pelo autor.
\end{abstract}

Palavras-chave: Teoria da Literatura; História da Crítica; Desconstrução.

Abstract: Review of Teoria da Literatura e História da Crítica: momentos decisivos, by Nabil Araújo. I will discuss, chapter by chapter, the central issues addressed in the book, aiming to shed light on the network of theoretical, critical and philosophical references used by the author.

Keywords: Theory of Literature; History of Criticism; Deconstruction.

ARAÚJO, Nabil. Teoria da Literatura e História da Crítica: momentos decisivos. Rio de Janeiro: EdUERJ, 2020.

Teoria da Literatura e História da Crítica: momentos decisivos, de Nabil Araújo (UERJ), reivindica a irredutibilidade do caráter de conflito inerente aos diferentes métodos de leitura e julgamento dos textos literários e figura, por este motivo, como uma contribuição teórica e historiográfica decisiva num momento em que tal diversidade parece, mais uma vez, animar as acusações de "crise dos estudos literários".

A problemática do conflito entre os métodos não é estranha à obra de Araújo. Basta recordar trabalhos anteriores que não apenas tematizam o confronto entre posições antagônicas em questões de teoria e de crítica, mas também, no mesmo gesto, antagonizam com nomes de peso, como Leyla Perrone-Moisés (ARAÚJO, 2016a), Luiz Costa Lima (ARAÚJO, 2016b), Franco Moretti (ARAÚJO, 2016c), Sandra Vasconcelos (ARAÚJO, 2018), Ottmar Ette (ARAÚJO, 2019a). Ademais, o autor é conhecido por sua tese de doutorado, intitulada $O$ evento comparatista: na história da crítica / no ensino de literatura, que recebeu o Prêmio UFMG de Teses, em 2014, e o Prêmio ANPOLL de Teses, em 2016. São retomadas dela tanto a primeira parte de Teoria da Literatura e História da Crítica: momentos decisivos quanto a obra O evento comparatista: da morte da literatura comparada ao nascimento da crítica, publicada pela EdUEL em 2019. Também deriva da tese o projeto "Ensino de literatura e desenvolvimento da competência crítica: uma 'terceira via' didático-pedagógica", premiado pela Fundação Carlos Chagas em 2014, no qual é defendida justamente a pluralidade de princípios a partir da qual o ensino de literatura deve formar "leitores-críticos". É, portanto, seguro afirmar que a pesquisa acadêmica de Nabil Araújo é atravessada em boa medida pela preocupação com a diferença entre os inúmeros métodos de aproximação dos objetos literários, bem como pela possibilidade ou não de sua síntese ou convivência.

\footnotetext{
${ }^{1}$ Universidade de Minnesota/Twin Cities, Mineápolis, Minnesota, EUA; https://orcid.org/0000-0002-4335-789X; thn.santana@gmail.com
} 
Talvez seja exatamente a obra aqui resenhada aquela que melhor expressa tal preocupação, traduzida, num primeiro momento, no questionamento do lugar da teoria da literatura, disciplina acadêmica cuja mais importante sistematização do século XX pode ser localizada na clássica Theory of Literature (1949), de René Wellek e Austin Warren. Valendo-se da "lógica da pergunta e resposta", teorizada por Hans-Georg Gadamer em Verdade e método (1960), Araújo buscará definir a que pergunta um manual como a Theory responde, na medida em que, para Gadamer, "a lógica das ciências do espírito é uma lógica da pergunta" (GADAMER apud ARAÚJO, 2020, p. 26) para a qual todo texto é uma resposta. Tal definição se mostrará especialmente árdua no caso de uma obra como a de Wellek e Warren, dada sua cristalização como obra clássica, fazendo com que esta seja, portanto, a primeira grande contribuição do estudo de Araújo: a recontextualização "[d]o problema associado à imagem corrente da Theory", através de sua reinserção "no horizonte-de-pergunta no qual ele se instaura como verdadeira questão" (Ibid., p. 27).

A pergunta para a qual a obra de Wellek e Warren serve de resposta fora inaugurada pela Crítica da faculdade do juízo (1790), de modo que, defende Araújo, a Theory pode ser encarada como uma resposta kantiana a Kant. Resposta kantiana, pois pretende assegurar "uma base racional para o estudo da literatura" por meio da identificação da "estrutura de normas [...] que têm que ser extraídas de cada experiência individual de uma obra de arte e que, juntas, constituem a obra de arte genuína como um todo" (WELLEK apud ARAÚJO, 2020, p. 29). Sobre tal procedimento, os autores da Theory afirmarão abertamente se tratar de um "argumento kantiano", que, somado às ideias de experiência estética presentes no penúltimo capítulo do manual, constitui o que Araújo afirma ser uma "resposta kantiana". Mas resposta kantiana $a$ Kant, pois se a Theory pretende assegurar as bases epistemológicas para a elaboração de um conhecimento seguro a respeito de objetos estético-literários, ela responde à tripartição kantiana dos domínios cognitivo, moral e estético, tratados em cada uma das "três Críticas" do filósofo alemão. Isso porque, conforme afirma Araújo por meio de Gadamer, Kant garante apenas ao primeiro e ao segundo domínios a possibilidade do conhecimento, restando ao terceiro a definição de "princípio subjetivo" (GADAMER apud ARAÚJO, 2020, p. 39) a partir do qual seria inviável erigir uma ciência. Apreende-se, portanto, da filosofia kantiana:

(a) [a] restrição do conceito de gosto ao domínio da faculdade do juízo, a fim de conferirlhe independência e autonomia; e, a um só tempo, (b) [a] restrição do conceito de conhecimento aos domínios da razão teórica e da razão prática, isto é, aos domínios contemplados, respectivamente, pela primeira e pela segunda Críticas (depreendendo-se daí a exclusão da possibilidade de conhecimento no domínio contemplado pela terceira Crítica). (Ibid., p. 37)

É diante da impossibilidade da fundamentação racional do domínio estético que a Theory deve ser compreendida como resposta, na medida em que confere ao estudo literário a segurança epistemológica vetada pela Crítica da faculdade do juízo. Araújo defende que tal segurança é explicitada numa pouco comentada conferência de 1950, na qual Wellek observa que se Kant "raramente trata de enfrentar o domínio concreto da arte", por outro lado ele "sugeriu ou antes reavivou um critério muito importante para o julgamento da arte: a analogia do organismo" (Ibid, p. 46). Segundo Araújo, Wellek faz referência à segunda seção da Crítica da faculdade do juízo e propõe a partir dela que a "harmonia das partes, unidade, totalidade, com cada membro tendo sua própria função no sistema" pode ser encarada como o "padrão para o juízo estético: quanto mais complexa a obra de arte, quanto mais [bem] composta, maior a totalidade, maior a beleza" (Ibid., p. 48). Aí está justamente a resposta a Kant: desenvolvendo uma sugestão do filósofo que, entretanto, não é explicitamente postulada, mas sugerida, Araújo demonstra que para Wellek a própria terceira Crítica oferecia a resposta para o vazio da 
fundamentação estética que ela mesma inaugurava. Tal é, portanto, a "estrutura de determinação" formal a que se refere a Theory, pretensamente retirada de uma sugestão de Kant, e a partir dela é possível concluir que a "abordagem intrínseca" da literatura deva se sobrepor àquela "extrínseca" - para nos atermos à terminologia popularizada por Wellek e Warren.

No próximo capítulo, Araújo defende que a saída pela analogia entre a obra de arte e um organismo vivo não é a única resposta ao problema da fundamentação estética inaugurado por Kant, mas apenas uma entre outras possíveis. Com Gadamer, o autor afirma (Ibid., p. 57) que há, ainda, ao menos duas outras respostas ou "percursos", sendo o primeiro "aquele que, partindo de certo deslocamento de ênfase do 'gosto' [Geschmack] para o 'gênio' [Genie] sugerido na Crítica da faculdade do juízo, desembocará na "estética do gênio", hegemônica "sob a égide da ideologia romântica" e tornada "científica" sob "a égide da ideologia positivista"; e o segundo "seria aquele que, partindo do desenvolvimento" - também engendrado pela Crítica da faculdade do juízo - "do conceito de 'gênio' em direção a um abrangente conceito de 'vida', desembocará na formulação do conceito de 'vivência' [Erlebnis] por Dilthey", garantindo aí "uma visada hermenêutica nas humanidades". No contexto da Theory, tais formas alternativas de responder à pergunta kantiana são identificadas, respectivamente: (1) no lansonismo em crítica acadêmica (exemplificável na obra de Gustave Rudler), que sintetiza e propaga a referida passagem do "gosto" para o "gênio" sob um viés historicista e positivista; e (2) na obra de Leo Spitzer, que, por meio de seu método "filológicohermenêutico" reverbera a resposta de Dilthey à pergunta kantiana. Evocando a erudição dos comentários de Araújo em cada uma dessas "respostas", serei sucinto em sua descrição.

Em certa altura da Theory, Wellek e Warren afirmam que seu manual diferirá de duas outras respostas ao problema de "como lidar intelectualmente com a literatura" - sendo a primeira delas a simples transposição dos métodos das ciências naturais para os estudos literários. Tal transposição é exemplificada pelo trabalho do crítico francês Gustave Rudler, cujo cientificismo sui generis será, então, analisado por Araújo. O trajeto apresentado pelo autor levará até o método de Gustave Lanson, hegemônico na França na transição entre os séculos XIX e XX e cujo "cientificismo brando" baseado na "descrição de individualidades" literárias - reivindicando as contribuições de Sainte-Beauve e reconhecendo "a incontornável subjetividade no trato com textos literários" (Ibid., p. 115) - representará um eco da leitura de Kant na França promovida décadas antes por de Mme. de Staël. Trata-se especificamente da leitura de Kant feita pelos autores românticos, onde a passagem de ênfase do "gosto" para o "gênio" balizará as questões estéticas dali em diante - ainda que, a certa altura, sob vestes cientificistas, como no caso de Lanson e dos lansonianos.

Madame de Staël é justamente a figura disseminadora do pensamento kantiano na França. Araújo afirma que a presença das ideias estéticas do filósofo alemão em De la littérature (1800), obra concebida na esteira da Revolução Francesa, compreende apenas a fase "pré-crítica" de Kant, isto é, anterior à elaboração de suas três principais obras, notadamente à Crítica da faculdade do juízo. Assim, naquela altura, Staël faz referência às Observações sobre o sentimento do belo e do sublime (1764), de Kant, e lança mão, segundo Araújo, de uma noção de "homem superior", caracterizado por algo como uma sensibilidade elevada - alcançada, por sua vez, por meio de certa "imaginação melancólica" (Ibid., p. 135) que o período pósrevolucionário exigiria. Nada mais contrário às ideias da própria Staël em De l'Allemagne, elaborado uma década depois da publicação do De la littérature: em contato com as "três Críticas" kantianas, a autora sacramenta, finalmente, na França, a ênfase no indivíduo na avaliação de questões estéticas e a derrocada dos valores clássicos como fins em si mesmos: "a grande lição kantiana sobre a qual então insiste Staël é mesmo a da impossibilidade de se determinar a universalidade do belo com base na agradabilidade do mesmo" (Ibid., p.140). A impossibilidade de determinação objetiva do belo, oposta à noção de gosto universal encampada em De la littérature, coloca Mme. de Staël como uma das figuras centrais na 
disseminação da noção de "gênio" em contraposição à autoevidência objetiva dos atributos estéticos conforme prescritos pela preceptística clássica. Ora, tal transição é justamente o que chegará até Lanson e Rudler, na forma cientificista, fazendo com que o manual do último, no contexto da Theory, possa ser considerado, também ele, como representativo de certa resposta a Kant.

O outro percurso de fundamentação estético-literária concorrente na Theory corresponde ao método de Leo Spitzer. Wellek e Warren afirmam que o crítico fracassa metodologicamente ao subordinar, em sua obra, o "material linguístico" a um "inconfesso pressuposto psicológicoideológico" (Ibid., p. 159) que extrapola, a princípio, as relações internas dos textos. Araújo dedica um capítulo, então, à descrição da abordagem filológico-interpretativa de Spitzer, na qual, partindo da análise do material linguístico dos objetos literários, ele avança à compreensão da "experiência interior" do poeta (Ibid., p. 163). Mais importantemente, a união do polo linguístico com a "experiência interior", a passagem de um para o outro e vice-versa, deve ser realizada, em primeiro lugar, "a partir da superfície em direção ao 'centro vital interno' da obra de arte [...] observando detalhes na aparência superficial da obra particular"; depois, "agrupando esses detalhes e procurando integrá-los num princípio criativo que possa ter estado presente no espírito do artista", para, enfim, fazer "o percurso de volta a todos os outros grupos de observações de modo a descobrir se a 'forma interna' que se construiu provisoriamente oferece uma descrição do todo" (SPITZER apud ARAÚJO, 2020, p. 184-185). Trata-se de uma trajetória circular, ou do próprio "círculo hermenêutico" teorizado por Dilthey a partir de Schleiermacher. Araújo chama este processo de "transmutação hermenêutica da filologia".

Araújo explicita, então, os outros elementos que unem o pensamento crítico de Spitzer ao de Dilthey, ao método hermenêutico desenvolvido pelo último. Torna-se possível, assim, afirmar que também o crítico austríaco responde a Kant na medida em que se vale das ideias de Dilthey, pois este, ao lançar mão do conceito de vivência [Erlebnis], busca precisamente realizar um gesto de retorno ao filósofo alemão. Tal conceito, "baseado na doutrina da 'elevação do sentimento de vida" e remetendo a "uma instância anterior à própria separação entre gênio e gosto" (Ibid., p. 167-168), será abertamente retomado por Spitzer e, por este motivo, figurará como a última das respostas a Kant no universo da Theory.

Encerrando a primeira parte do estudo, Araújo discute o caráter de incontornável disputa que atravessa o que ele chama de modernidade crítica. Três respostas kantianas a Kant epitomadas em Wellek, em Rudler e em Spitzer - tentam preencher a ausência de fundamentação estética decorrente da Crítica da faculdade do juízo; três respostas possíveis, Araújo afirma, "mas não compossíveis" (Ibid., p. 226). Trata-se de possibilidades sugeridas pelo próprio texto kantiano e eventualmente desenvolvidas à revelia deste, mas sem que um critério epistemologicamente neutro lhes seja capaz de garantir sustentação, de maneira que as três respostas constituem, cada uma delas, propostas "arriscadas", sem garantias (Ibid., p. 237). No entanto, os dois últimos subcapítulos da primeira parte do livro são dedicados a provar que "a estrutura indecidivelmente conflitual do responder", discutidos até aqui em termos de uma modernidade crítica inaugurada por Kant, pode ser encontrada tanto na "pré-modernidade" quanto na "pós-modernidade". Novamente, não será possível desenvolver em detalhes os argumentos presentes no livro, mas, resumidamente, Araújo compreende no chamado período pré-moderno a "fórmula mimética" de Aristóteles como uma resposta a Platão (Ibid., p. 246) e, no período pós-moderno, o pensamento estético de Nietzsche como uma resposta a Kant e a Aristóteles (a um só tempo). Assim, o autor parece sugerir que a indecidibilidade da resposta à questão do fundamento de avaliação estética não se revela historicamente contingente - e restrita à "modernidade crítica" -, mas talvez como "aquele aspecto universal que Gadamer se esforçou, um dia, por atribuir ao fenômeno hermenêutico" (Ibid., p. 277).

Chega-se, então, à segunda parte do livro, dedicada à discussão dos pressupostos e métodos de um gênero de trabalho acadêmico ainda pouco explorado no Brasil: a História da 
Crítica, gênero do qual, aliás, toda a primeira parte do livro seria uma realização. Atesta-se, então, em termos metodológicos, a impossibilidade de eliminação da heterogeneidade constitutiva da aproximação de textos literários pela teoria ou pela crítica: Araújo buscará explicitar o elemento conflitual inerente à história da crítica.

O primeiro capítulo dessa parte discute as formas através das quais o tema da nação surge nas historiografias da crítica do final do século XIX e primeira metade do século XX. Partindo de um trecho pouco discutido do conhecido ensaio "Tradição e talento individual", de T. S. Eliot, Araújo sublinha sua reivindicação por uma crítica especificamente inglesa, em detrimento daquela produzida na França, hegemônica naquela altura. Os esforços de Eliot em direção a uma "critic turn of mind" o faz conceber evolutivamente algo como a sucessão de figuras notórias da prática da crítica no contexto inglês, de Dryden a Matthew Arnold, em contraposição ao "ésprit critique" francês defendido por Ferdinand Brunetière e tantos outros. Araújo aponta que em Eliot a defesa de uma história da crítica tipicamente inglesa representa uma forma de organizar de maneira "natural" a sucessão de julgamentos de obras literárias. Naturalidade, entenda-se, garantida pela coesão que a nação assegura ao arranjo dos diferentes críticos e de suas opiniões. Nesse sentido, o gentílico "inglês" (como "francês", "alemão", etc.) associado a um ou outro agrupamento de críticos permitiria ao estudioso submeter a um critério relativamente seguro qualquer heterogeneidade metodológica que possa se apresentar. Por outro lado, bem mais revolucionária, prossegue Araújo, é a proposta de George Saintsbury décadas antes, que, diferentemente daqueles que como Eliot e Brunetière empreenderam uma organização nacional da história dos julgamentos literários, busca arranjá-la por meio da própria função do julgamento ou dos critérios de avaliação, atravessando nações e línguas. À "crítica renascentista", por exemplo, Saintsbury associará os autores italianos, a Plêiade francesa e os críticos elizabetanos; à "moderna", semelhantemente, associará nomes das mais diversas origens: "Dryden e Boileau, Coleridge e os Schlegel, Arnold e Sainte-Beuve podem ser colocados lado a lado e comparados entre si por serem críticos, isto é, por se dedicarem à mesma atividade, e não por pertencerem a esta ou àquela 'nação' ou 'raça', por escreverem nesta ou naquela língua nacional" (Ibid., p. 297).

Araújo, então, relaciona tais expedientes historiográficos com as diferentes maneiras de encarar e escrever a história descritas por Nietzsche na conhecida Segunda consideração intempestiva (1874). Definido como aquele que "olha para trás, com fidelidade e amor, lá para o lugar de onde veio e no qual se criou" (NIETZSCHE apud ARAÚJO, 2020, p. 302), o historiador antiquário atua por meio de "um processo de identificação" e busca "reconstituir a história desse lugar pátrio" (NIETZSCHE apud ARAÚJO, 2020, p. 302), além de acreditar "estar escrevendo uma autobiografia" (Ibid., p. 302). Ora, embora Brunetière e Eliot compartilhem com os "historiadores antiquários" a crença na ligação entre criticidade e nação, afirma Araújo, ambos colocam a "veneração do passado" nacional a serviço de uma preocupação contemporânea e em direção ao futuro, aproximando-se, em alguma medida, portanto, dos "historiadores monumentais". Trata-se, ambos, de "historiadores nacionais fortes", conforme Araújo os classifica recuperando a terminologia empregada por Harold Bloom na descrição da "angústia da influência". No entanto, ainda que difiram dos historiadores antiquários pelas demandas presentes e futuras que os mobilizam, o "conforto" e a "naturalidade" proporcionada pela coesão a priori do critério nacional impede que suas historiografias possam ser enquadradas no que Nietzsche chama, enfim, de "espécie crítica de história". Nesta categoria Araújo inclui justamente Saintsbury. A libertação representada por essa prática historiográfica é definida por Nietzsche da seguinte maneira: "somente aquele a quem uma aflição presente oprime o peito e que quer livrar-se do fardo a qualquer preço necessita de uma história crítica, isto é, que julga e que condena" (NIETZSCHE apud ARAÚJO, 2020, p. 312). Ou, adiante: "Ele precisa ter a força, e aplicá-la de tempos em tempos, para esfacelar e dissolver um passado, a fim de poder viver: isso ele alcança porque o arrasta 
para diante do tribunal, penosamente o inquire e, finalmente, o condena" (NIETZSCHE apud ARAÚJO, 2020, p. 312). Para Araújo (Ibid., p. 313), quando Saintsbury "inquire" e "desmascara" o "glorioso passado nacional" da crítica francesa, ele o faz não em benefício da excepcionalidade da crítica inglesa, como Eliot, mas "em nome da depuração da crítica literária como 'função do julgamento' ou 'exercício raciocinado do gosto"”, livre “de qualquer restrição linguístico-nacional que se queira lhe impor". Portanto, sua intenção não é aniquilar "o legado crítico francês", mas submetê-lo a um critério não circunscrito à língua e à nação, abrindo o caminho para uma prática historiográfica diversa em relação àquela praticada até ali.

Araújo prosseguirá demonstrando a maneira através da qual o procedimento de Wellek novamente ele, mas encarado, desta vez, como historiador da crítica e não apenas como teórico - reconhece a precedência e a importância do trabalho de Saintsbury na concepção de seu próprio empreendimento historiográfico, a saber, a monumental History of Modern Criticism. No entanto, em Wellek surgirá a pergunta fundamental subsequente ao abandono da nacionalidade como critério para o arranjo da crítica: de que maneira organizar historicamente autores e ideias tão díspares? A grande questão a ser enfrentada a partir de agora, afirma Araújo, é "a da comparabilidade do heterogêneo" (Ibid., 315). Wellek reconhece o problema e decidese pela eleição de um critério controverso, a saber, precisamente a "moderna teoria da literatura" proposta pela própria Theory of Literature, de maneira a selecionar e avaliar a heterogeneidade constitutiva da história da crítica em função do que "é previsto e determinado pelo parâmetro teórico pré-estabelecido" (Ibid., p. 320). Ao longo dos anos, no entanto, Wellek renunciará resignadamente ao seu empreendimento "evolutivo e teleológico" em benefício do "reconhecimento de uma pluralidade e uma simultaneidade de vertentes críticas enraizadas em, potencialmente, "qualquer coisa no passado", abrindo as portas "para uma historiografia da crítica que, buscando fazer justiça ao que outrora fora relegado como ultrapassado ou sem relevância para o presente e o futuro da crítica, busque resgatar, reconstituir e preservar o máximo de perspectivas críticas passadas" (Ibid., p. 325).

Anuncia-se, assim, a grande contribuição de Araújo na segunda parte de seu livro: a proposta de uma prática historiográfica zelosa pela pluralidade inerente a qualquer tentativa de organizar no tempo as diferentes maneiras de julgar os objetos literários. Após discorrer brevemente sobre as histórias da crítica pós-wellekianas nos Estados Unidos, o autor analisará, no capítulo seguinte, a obra de Dominick La Capra. Buscando precisamente "escrever uma história que faça justiça [...] à 'heterogeneidade radical' e à 'dialogicidade interna' da crítica contemporânea", LaCapra propõe um modelo de historiografia inicialmente baseado na ideia de "repetição com mudança" de Derrida: "Essa temporalidade [...] 'também situa o crítico numa relação transferencial com o 'objeto' de estudo; ela nega a possibilidade de total domínio mas também abre aquela de um intercâmbio ou 'diálogo' mais bem informado e autocrítico com o passado" (LACAPRA apud ARAÚJO, 2020, p. 348). Se Saintsbury propôs uma espécie de primeiro nível de transversalização da história da crítica ao realizá-la sem se ater ao "Espírito Nacional", LaCapra proporá, por outro lado, um segundo nível, no qual a transversalidade operaria não somente em relação a "tradições linguístico-literárias diversas, mas também às diversas escolas, correntes ou perspectivas teóricas" (Ibid., p. 349). Cabe destacar aqui, brevemente, que Araújo concebe o projeto lacapriano como uma "recusa" da proposta metacrítica de Jonathan Culler, pautada, esta, pela possibilidade de uma síntese e de uma coesão interna das diversas correntes críticas: "assim sendo, a insistência lacapriana em conceber a 'cena crítica corrente' como uma 'arena' de práticas discursivas concorrentes deveria ser tomada antes como uma recusa, e, mesmo, uma reversão, ao modo de um desarquivamento, da síntese didática culleriana" (Ibid., p. 356)

Se LaCapra imagina tal "arena" como um ponto de partida historiográfico, Araújo a concebe, no último capítulo do livro, como um ponto de chegada do trabalho do historiador da crítica. Partindo de Derrida, o autor propõe uma concepção de história da crítica que ele chama 
de monstruosa ou teratológica, na qual são desveladas as forças teóricas anteriores à estabilização institucional ("ismos", "pós-ismos", etc.) a que elas frequentemente são sujeitadas:

[uma monstruosidade] nunca apresenta a si mesma; ou então, se vocês preferirem, ela apenas apresenta a si mesma, isto é, deixa-se ser reconhecida, permitindo-se ser reduzida àquilo que é reconhecível; isto é, a uma normalidade, uma legitimidade que não é ela [...]. Uma monstruosidade só pode ser "desconhecida" (méconnue), isto é, não reconhecida [unrecognized] e mal compreendida [misunderstood]. Ela só pode ser reconhecida depois, quando tornou-se normal ou a norma (DERRIDA apud ARAÚJO, 2020, p. 365).

Contra a "apropriação/assimilação/aculturação de eventos do passado a serviço de objetivos diversos", ou, ainda, contra a normalização cognitiva e metodológica perpetrada pelas historiografias disciplinares, Araújo (Ibid., p. 372) propõe, com Derrida, uma história da crítica de feição monstruosa como antídoto contra a "domesticação" institucional das práticas acadêmicas de leitura literária. O último parágrafo do livro é, nesse sentido, lapidar:

Contrariamente às espécies historiográficas orientadas para o passado crítico, que têm na memória o seu grande instrumento, seja para antiquarizar, para monumentalizar ou para criticar o objeto dessa memória, a espécie teratológica caracterizar-se-ia, antes, por um golpe de desmemória, por um monstruoso esquecimento em face dos ditos grandes marcos da teoria crítica ocidental acarretando o desarquivamento, a reversão dos mesmos até o ponto em que a crítica pudesse, então, uma vez mais, acontecer (Ibid., p. 376).

Encerra-se assim o livro de Araújo. O percurso que teve início com o apontamento da inescapável heterogeneidade interna da teoria da literatura, erigida, ela própria, em meio a outras respostas ao mesmo problema de que se ocupa, termina com a proposta, retrospectiva e prospectiva, de uma história teratológica da crítica. A conclusão parece ser a de que a teoria da crítica e a própria crítica, quando analisadas em sua abrangência histórica, não podem nem poderão contar com um critério ou ponto de fuga meta-histórico capaz de superar definitivamente suas discordâncias internas - discordâncias estas constitutivas e produtivas, portanto.

\section{REFERÊNCIAS}

ARAÚJO, Nabil. Contra a teoria: do romance (entre a lei do gênero e a lei do gênio). In: ARAÚJO, Nabil; TEIXEIRA, Maria Juliana Gambogi; WERKEMA, Andréa (Orgs.). Variações sobre o romance II. Rio de Janeiro: Makunaima, 2018. p. 269-302.

. Do passado como futuro da crítica: "competência performativa" e "formas de escrita" nos Estudos Literários. Aletria, Belo Horizonte, v. 29, n. 3, 2019a, p. 97-116.

. O evento comparatista: da morte da literatura comparada ao nascimento da crítica.

Londrina: EdUEL, 2019b.

. Que fim levou a teoria da crítica literária? In: ARAÚJO, Nabil (Org.). A crítica literária e a função da teoria: reflexão em quatro tempos. Belo Horizonte: Viva Voz, 2016a, p. 5-16.

. O sequestro da crítica na teoria literária (à) brasileira. In: ARAÚJO, Nabil (Org.). A crítica literária e a função da teoria: reflexão em quatro tempos. Belo Horizonte: Viva Voz, 2016b, p. 35-55. 
Teoria da Literatura e História da Crítica: momentos decisivos. Rio de Janeiro: EdUERJ, 2020.

. Vista de longe, a literatura é o que desaparece... (Acerca de um fracasso programático em Franco Moretti). In: ARAÚJO, Nabil; SOARES, Marcus Vinicius; WERKEMA, Andréa (Orgs.). Variações sobre o romance. Rio de Janeiro: Makunaima, 2016c, pp. 259-272.

Thiago Santana é graduado em Letras e mestre em Teoria da Literatura e Literatura Comparada pela Universidade Federal de Minas Gerais. Atualmente, cursa doutorado na Universidade de Minnesota/Twin Cities. Publicou artigos em periódicos acadêmicos da área de Estudos Literários, focados em questões da História da Crítica, Teoria da Literatura e Classicismo.

Submetido em 10/06/2020

Aprovado em 15/07/2020 